\title{
A Means-End Analysis of Consumers' Perceptions of Virtual World Affordances for E-commerce
}

\author{
Minh Quang Tran ${ }^{1}$, Shailey Minocha ${ }^{1}$, Dave Roberts ${ }^{1}$, \\ Angus Laing ${ }^{2}$, and Darren Langdridge ${ }^{3}$ \\ ${ }^{1}$ Centre for Research in Computing, The Open University, UK \\ ${ }^{2}$ School of Business and Economics, Loughborough University, UK \\ ${ }^{3}$ Department of Psychology, The Open University, UK \\ \{m.tran, s.minocha, d.roberts, d. langdridge\} @open.ac.uk, \\ a.w. laing@lboro.ac.uk
}

\begin{abstract}
Virtual worlds are three-dimensional (3D) persistent multi-user online environments where users interact through avatars. The affordances of virtual worlds can be useful for business-to-consumer e-commerce. Moreover, affordances of virtual worlds can complement affordances of websites to provide consumers with an enhanced e-commerce experience. We investigated which affordances of virtual worlds can enhance consumers' experiences on ecommerce websites. We conducted laddering interviews with 30 virtual world consumers to understand their perceptions of virtual world affordances. A means-end analysis was then applied to the interview data. The results suggest co-presence, product discovery, 3D product experience, greater interactivity with products and sociability are some of the key virtual world affordances for consumers. We discuss theoretical implications of the research using dimensions from the Technology Acceptance Model. We also discuss practical implications, such as how virtual world affordances can be incorporated into the design of e-commerce websites.
\end{abstract}

Keywords: Consumer experience, e-commerce, interaction design, laddering interviews, means-end analysis, qualitative research, user experience, virtual worlds.

\section{Introduction}

Virtual worlds, such as Second Life [1], are being used by businesses for real world ecommerce. For example, Toyota and Reebok have created virtual stores and showrooms in Second Life for consumers to interact with virtual simulations of their real world products [2]. These and other real world businesses that create a presence in virtual worlds can increase their engagement with consumers [3] and enhance the value of their brands [4]. Given the potential benefits of using virtual worlds for real world e-commerce, researchers are beginning to investigate how virtual worlds can be better utilised by businesses [5].

In this paper, we investigated which virtual world affordances facilitate ecommerce from the consumer's perspective. For our study, we defined affordances as 
features of a technology that determine ways a technology can be used [6]. Our investigation is based in Second Life. Second Life (http://secondlife.com) is a virtual world that was launched in 2003 and continues to attract 800,000 visitors each month. It supports many activities, including education, socialising, gaming and e-commerce. The e-commerce activity in Second Life mostly involves virtual items [7]. However, an understanding of the affordances for e-commerce with virtual items is useful for understanding how e-commerce in virtual worlds with real items can occur.

Some virtual world affordances used for e-commerce with virtual items are likely to be the same affordances used for e-commerce with real items. For example, virtual worlds afford the rendering of 3D objects in a 3D environment. This affordance allows consumers to have a virtual experience with real or virtual products, which can help consumers to learn about and evaluate products before buying [8]. Furthermore, the affordance of a persistent multi-user environment enables and sustains online communities. Online communities are known to influence consumers' experiences [9] regardless of whether the consumption is real or virtual. The aim of this paper is to identify the virtual world affordances that enhance consumers' real world ecommerce experiences. Our investigation has led to an understanding of when and why certain virtual world affordances are useful for e-commerce.

\section{Research Question}

The research question we have addressed is "which affordances of virtual worlds can enhance consumers' e-commerce experiences?" The research question has been investigated through laddering interviews and means-end analysis. These techniques are commonly applied in consumer research to understand consumers' preferences for brands, advertisements and products [10]. We have applied these techniques to understand consumers' perceptions of virtual world affordances for e-commerce. Laddering interviews were used to elicit the underlying reasons consumers have for preferring certain affordances. Means-end analysis was then used as a structured method to analyse the qualitative data from the laddering interviews [11].

\section{Background}

The theoretical framework of this study is based on the concept of the service encounter. The service encounter includes all the interactions that the consumer performs during the provision of a service [12]. In the context of e-commerce, the service encounter centres on the online purchase transaction. Moreover, the pre-purchase and post-purchase interactions are also a part of the service encounter. In this study, we have elicited consumers' perceptions of how virtual world affordances can enhance the e-commerce service encounter.

An important concept within the e-commerce service encounter is the consumer's ability to move between different online and offline service channels. Consumers choose appropriate service channels based on their needs during a service encounter. For example, additional support for the purchase can be provided through high street stores, telephone and mail-order catalogues [13]. This study starts with the premise 
that virtual worlds are able to address certain needs that consumers have during the ecommerce service encounter.

Virtual worlds are said to incorporate the convenience of e-commerce websites with the richness of interactions of high street stores [14], but there is little empirical evidence to support this claim. Despite their potential, virtual worlds seem to be under-utilised for real world e-commerce. Currently, in April 2011, there are only a small number of virtual worlds that support online purchasing of real world products: some examples of virtual worlds designed specifically for e-commerce are Avaya (http://avayalive.com), NearWorld (http://london.nearglobal.com), and Trillenium (http://www.trillenium.com). Part of the motivation for this paper is to examine the reasons for the under-utilisation of virtual worlds for real world e-commerce and to understand what can be done to increase their usage.

According to the Technology Acceptance Model [15], the usage of technology is determined mainly by perceived usefulness and perceived ease-of-use. However, given the relative novelty of virtual worlds, our investigation was conducted in an exploratory manner. We did not limit the study to only investigate pre-determined dimensions of technology use, such as perceived usefulness and perceived ease-ofuse; we allowed other dimensions to emerge from the data as well.

\section{Data Collection}

We conducted 30 interviews with participants who had e-commerce experience in Second Life. The participants also had e-commerce experience on websites. Participants were recruited and interviewed in Second Life through the use of avatars. The recruitment procedure and interview protocol were approved by our university's ethics committee. We also followed Second Life's community standards [16] to ensure that the study was not violating Second Life's usage policy.

To locate participants, we visited shopping and socialising areas in Second Life. In these areas, we scouted for prospective participants by first reading their user profiles. User profiles contain public information provided voluntary by the user. The user profiles were utilised as a preliminary screening tool. Based on the profiles, we could identify experienced users of Second Life and we could identify users who had shopping experiences in Second Life. Prospective participants were then sent a private text message (similar to an instant message (IM)) inviting them to participate in the research study. Those that agreed were given a virtual note card containing detailed information about the study and our contact information. A second note card was given to participants as a consent form. Participants were then asked if they were over 18. If they were over 18 , they were asked to consent to participate through text messaging.

Demographic information (real life age, real life gender, real life occupation, and country of residence for participants) was requested from participants at the end of each interview. Providing demographic information was optional. Thus, some participants did not reveal all their demographic information. With the information provided to us, we know that 13 males and 13 females participated. Four participants did not reveal their gender. Participants resided in USA (7), UK (3), Romania (3), Spain (2), New Zealand (2), Italy (2), India (2), France (1), Belgium (1), Australia (1) and Germany (1). Four participants did not reveal their country of residence. Participant's 
ages ranged from 18 to 55 . Eight participants did not reveal their age. The mean age of known participants was 29.1.

All the interviews were conducted in Second Life, using private text messaging. Interviews typically lasted 45 minutes to 1 hour. The interviews were conducted in English. Interviews were conducted between May 2010 and Dec 2010. Participants were given an honorarium worth two Great Britain pounds that was paid in Linden Dollars, Second Life's currency.

The interviews started with background questions to elicit participant's experiences of shopping in Second Life and shopping on websites. Participants were then asked to recall features of websites that they liked and disliked. This question was to prime participants so that they could more easily answer the main interview question. The main interview question was, "can you think of Second Life features that would make shopping on websites better or easier?

As participants recalled features, we proceeded to apply the laddering technique. The laddering technique involved asking a series of probing questions, such as 'why is the feature important to you?' The probes were meant to uncover participants' preferences for specific features of virtual worlds during the e-commerce service encounter.

\section{Data Analysis}

We analysed the interview data using means-end chain analysis [17]. The analysis started by extracting ladders, or means-end chains, from the data. Each ladder contains three components: an attribute, a consequence and a value.

- An attribute refers to any feature of the virtual world, but specifically something that can be interacted with or supports an interaction.

- A consequence is the outcome of performing the interaction.

- A value is the psychological need or desire associated with the consequence.

Each ladder represents participants' reasoning about why they think a feature of the virtual world is useful for e-commerce. An example of a ladder is: having avatars (attribute) to interact with real people (consequence) to feel a connection with others (value). Extracting ladders involved two steps: making annotations and linking the annotations.

1. Annotating involves identifying relevant segments of the data and describing them either as referring to an attribute, a consequence or a value. An additional description is given to the annotation that refers to its meaning. For example, an annotation could be: [value: connection with others]. For this annotation, 'value' refers to the ladder component and 'connection with others' refers to its meaning.

2. Linking annotations involves making explicit the connection between specific attributes, consequences and values that are mentioned by participants. The purpose is to create complete ladders with each of the three components: an attribute, a consequence and a value. 
In the excerpt below, we show an example of how the data is annotated and linked to create a ladder. The three components for this ladder are: [attribute: having avatars][consequence: interact with real people][value: connection with others].

Interviewer: Can you think about how things you know about Second Life may help make shopping on a website better?

Consumer27: The sense of companionship [value: connection to others]. When I shop in [Second Life] it's usually with a couple of girlfriends [consequence: interact with real people].

Interviewer: And why is it important that you can shop with others?

Consumer27: I value their opinions on style and I like to share in their pleasure at finding something that looks good on them. It's a social activity.

Interviewer: Do you think there is something else about Second Life that helps with the companionship?

Consumer27: <nods> well the high-bandwidth communication

Interviewer: What do you mean by that?

Consumer27: Not just chat, but being able to share visually

Interviewer: Share visually?

Consumer27: mmHmm (sic) I can try something on and my friends tell me how it looks on me [...] the 3D models could be made off of real clothes using real photo textures so the ingredients are there for this kind of experience. [attribute: having avatars]

The data was annotated by using a bottom-up strategy, that is, by working from the data instead of using pre-determined concepts. Through several iterations, the annotations were eventually consolidated into a set of 51 codes, comprising of 16 attributes, 19 consequences and 16 values. We list the codes in the next section.

\subsection{Codes Derived from the Annotation Process}

Table 1 shows our codes and their frequency of appearance in the data. The percentage represents the frequency of the code relative to the total number of ladders.

Table 1. Codes for attributes, consequences and values

\begin{tabular}{lllr}
\hline$\#$ & Code Name & Alternate Description & \% \\
\hline Attributes of Second Life & & \\
\hline 1 & Store attendants & Getting immediate help from business & $10.5 \%$ \\
2 & Teleportation & Instantly travelling to locations & $0.9 \%$ \\
3 & High graphic detail & High resolution of images and objects & $2.6 \%$ \\
4 & User generated content & Other users create objects in the world & $1.8 \%$ \\
5 & Access to websites & Easy to switch to and from websites & $4.4 \%$ \\
6 & Content creation tools & Tools for modifying in-world objects & $0.9 \%$ \\
7 & 3D environment & Environment is rendered in 3D & $15.8 \%$ \\
8 & 3D objects & Objects are rendered in 3D & $21.1 \%$ \\
9 & Multi-user & Sharing same environment with others & $9.6 \%$ \\
10 & Having avatars & Users embodied through an avatar & $7.9 \%$
\end{tabular}


Table 1. (Continued)

\begin{tabular}{|c|c|c|c|}
\hline \# & Code Name & Alternate Description & $\%$ \\
\hline \multicolumn{4}{|c|}{ Attributes of Second Life } \\
\hline 11 & Wide selection & Wide selection of products to browse & $1.8 \%$ \\
\hline 12 & Synchronous interactions & Interactions happen in real-time & $4.4 \%$ \\
\hline 13 & Alternative payment & Payment does not require a website & $3.5 \%$ \\
\hline 14 & Real world stores & Real stores have presence in-world & $2.6 \%$ \\
\hline 15 & Social network & Supports social networking & $9.6 \%$ \\
\hline 16 & Multimedia support & Support for audio and visual media & $2.6 \%$ \\
\hline \multicolumn{4}{|c|}{ Consequences of having the attributes } \\
\hline 17 & Avoid inconvenience & Avoid travel and weather of real world & $3.5 \%$ \\
\hline 18 & Interact with real people & Real people are controlling the avatars & $14.0 \%$ \\
\hline 19 & Remain logged in & No need to exit virtual world & $1.8 \%$ \\
\hline 20 & Visually presented & Products are visually represented & $11.4 \%$ \\
\hline 21 & Interaction history & Saved history of interactions & $2.6 \%$ \\
\hline 22 & Can listen to music & Hear music and ambient sounds & $0.9 \%$ \\
\hline 23 & Interactions are in-world & Familiar navigation and interface & $2.6 \%$ \\
\hline 24 & Fast purchase transaction & Transactions are done in 'one click' & $1.8 \%$ \\
\hline 25 & Shop with friends & Can shop in friend's presence & $4.4 \%$ \\
\hline 26 & Maintain anonymity & Person remains anonymous & $0.9 \%$ \\
\hline 27 & Learn about products & Feel they know more about products & $15.8 \%$ \\
\hline 28 & Attracted to products & Product becomes desirable & $3.5 \%$ \\
\hline 29 & More reason to buy & Gain reasons to make purchase & $1.8 \%$ \\
\hline 30 & No pressure to buy & No hassle from sales person & $1.8 \%$ \\
\hline 31 & Increased trust & Confidence in business or product & $10.5 \%$ \\
\hline 32 & Discover products & Discover products unexpectedly & $7.0 \%$ \\
\hline 33 & See something new & Impressed by the novel graphics & $1.8 \%$ \\
\hline 34 & Alternate identity & Create an alter ego & $1.8 \%$ \\
\hline 35 & Play with products & Interact with products & $12.3 \%$ \\
\hline \multicolumn{4}{|c|}{ Personal values expressed by consumers } \\
\hline 36 & Save money & Not wasting money on bad purchase & $2.6 \%$ \\
\hline 37 & Get immediate reply & Being attended to immediately & $1.8 \%$ \\
\hline 38 & More knowledge & Having more knowledge of products & $22.8 \%$ \\
\hline 39 & New experience & Experiencing something new & $5.3 \%$ \\
\hline 40 & Safety & Personal information kept private & $6.1 \%$ \\
\hline 41 & Familiar experience & Interacting in a 'natural' way & $3.5 \%$ \\
\hline 42 & Feel cared for & Sense of being attended to & $6.1 \%$ \\
\hline 43 & Informed decisions & Confidence in purchase decision & $13.2 \%$ \\
\hline 44 & Connection to brand & Relationship with brand & $0.9 \%$ \\
\hline 45 & Connection to virtual & Relationship with virtual community & $3.5 \%$ \\
\hline 46 & Feel welcomed & Feeling at ease in virtual world & $0.9 \%$ \\
\hline 47 & Disconnected from real & Forgetting about real world & $0.9 \%$ \\
\hline 48 & Enjoyment & Experience is 'fun' & $23.7 \%$ \\
\hline 49 & Connection to others & Relationship with individuals & $3.5 \%$ \\
\hline 50 & Freedom to play & Allowed to experiment with products & $2.6 \%$ \\
\hline 51 & Save time & Get things done faster in virtual world & $2.6 \%$ \\
\hline
\end{tabular}

The codes in Table 1 were used to derive ladders during the linking process. 


\subsection{Ladders Derived from the Linking Process}

Alongside the annotation process, ladders were derived through the linking process described above. 114 ladders were derived from the data: a mean of 3.8 ladders per participant. The ladders were then entered into LadderUX. LadderUX is a data analysis software package for laddering research [18]. The software creates hierarchical value maps based on the formula described in Reynolds and Gutman's seminal paper on laddering [17]. First, a matrix is created that cross-links all the codes. Each crosslink between codes is given a score depending on how frequently a link between the codes appears. Then, a map is generated based on the scores. Only those scores which are above a defined cut-off level are shown in the map. The researcher defines the cut-off level. Cut-off levels from 3 to 5 are most common in laddering research. The cut-off level we have used for our map is 4 (see Figure 1, section 6.2).

\section{Results}

In this section, we summarise the results of the analysis. First, we discuss the attributes, consequences and values. Then, we discuss the hierarchical value map and finally, we re-visit the research question of this paper. For the results section, participants are referred to as consumers.

\subsection{Summary of Attributes, Consequences and Values}

\section{Attributes}

Attributes are features of virtual worlds. The most frequently mentioned attributes by consumers are shown in Table 2 . Only attributes with a frequency higher than $9 \%$ are discussed in this paper. At the $9 \%$ cut-off, we found a close fit between the number of elements in the summary tables (e.g. Table 2) and the number of elements in the hierarchical value map. Attributes that are related are grouped and discussed together.

Table 2. Summary of most frequently mentioned attributes

\begin{tabular}{llll}
\hline Attribute Code & Code Frequency & $\begin{array}{l}\text { Attribute } \\
\text { Group }\end{array}$ & $\begin{array}{l}\text { Grouped } \\
\text { frequency }\end{array}$ \\
\hline 3D objects & $21.1 \%$ & 3D aspects & $36.9 \%$ \\
3D environment & $15.8 \%$ & Social aspects & $29.7 \%$ \\
\hline Store attendants & $10.5 \%$ & & \\
Social network & $9.6 \%$ & $9.6 \%$ & \\
Multi-user & 9
\end{tabular}

\section{Attribute group: 3D aspects}

The first grouping that emerged is 3D aspects, which was present in $36.9 \%$ of the ladders. This relates to $3 \mathrm{D}$ objects and the $3 \mathrm{D}$ environment of virtual worlds. It is not surprising these attributes are mentioned most frequently. The difference between the 
$3 \mathrm{D}$ environment in virtual worlds and the 2D display on websites is easy for consumers to notice.

Consumer3: The layout when you shop in [Second Life] is way nicer than on the average website. I mean, ok, [Second Life] is 3D whereas a site is merely 2D. It's just that the presentation and the [angle of] perception are so much better used in [Second Life], which makes you wanna (sic) buy stuff.

When consumers discuss the 3D aspects, they usually refer to navigation and perception. Navigation relates to being able to walk through a virtual store to browse virtual shelves and see rows of virtual products. This simulates the navigation experience of a real store. Perception is about having objects represented with depth (hence, 3D). Both navigation in a $3 \mathrm{D}$ environment and $3 \mathrm{D}$ perception add to the sense of realism.

Consumer16: With $3 D$ it gives it a little better feel of what you are getting into.

Interviewer: Can you say a bit more about what you mean by 'feel'?

Consumer16: Well to simplify. Compare Sega to Playstation 3. Sega is flat images, 16-bit. Play station has $3 D$ graphics. Which appeals to people more? Playstation 3 of course because it gives people that sense of realness. It's as if the objects are there in front of you vs on paper.

Consumers report the 3D aspects in terms of its visual appeal. "The [3D] interface is more seductive than flat corporate web sites" (Consumer5). Beyond visual appeal, $3 \mathrm{D}$ aspects allow greater interactivity.

Consumer23: It's just fun [...] you feel like its [real life]

Interviewer: Can you tell me what is it about the '[real life] feeling' that makes it fun?

Consumer23: You just feel like you're actually in a shop, not flicking thru a $\operatorname{mag}($ sic).

\section{Attribute group: Social aspects}

The second grouping that emerged is social aspects, which was present in $29.7 \%$ of the ladders. Social aspects entail having other people around who are also participating in the shopping experience. These could be strangers, friends or sales personnel.

Consumer1: Make [shopping] more attractive. Event organisation, product presentations, and people we can talk to about their products, etc. I am reminded of the Reebok SL shop. It was empty, strangely dead. Too bad, they were selling interesting things for a good price

Interviewer: Can you tell me about it being empty? Why is this a bad thing?

Consumer1: Their shop was like [16 $\left.\mathrm{km}^{2}\right]$ for only 10 articles and nobody in there. [...] It's like entering a huge empty mall. It makes me think about "night of the living dead".

Consumers appreciate having others around, especially people they are familiar with and can talk to. 
Consumer26: When you go shopping it's nice especially with friends.

Interviewer: Why is it nice to shop with friends?

Consumer26: That it's not boring [...] you [can] talk and not walk alone through the store.

Interaction with sales personnel is also frequently mentioned as an advantage of shopping in virtual worlds.

Consumer13: [Store attendants can] help the customer find the product that best suits them, and answer questions about products. I guess going with the jewellery thing, I'm thinking of a boutique kind of experience.

\section{Consequences}

Now we look at the consequences of utilising virtual worlds for e-commerce. Consequences relate to outcomes of utilising virtual world features. Table 3 lists consumer's most frequently mentioned consequences. As with the attributes, we only summarise the consequences with a frequency over $9 \%$.

Table 3. Summary of most frequently mentioned consequences

\begin{tabular}{|c|c|c|c|}
\hline Consequence Code & $\begin{array}{l}\text { Code } \\
\text { Frequency }\end{array}$ & $\begin{array}{l}\text { Consequence } \\
\text { Group }\end{array}$ & $\begin{array}{l}\text { Grouped } \\
\text { Frequency }\end{array}$ \\
\hline Learn about products & $15.8 \%$ & & \\
\hline Play with products & $12.3 \%$ & Product fidelity & $39.5 \%$ \\
\hline Visually presented & $11.4 \%$ & & \\
\hline Interact with real people & $14.0 \%$ & $\begin{array}{l}\text { Interact with real } \\
\text { people }\end{array}$ & $14.0 \%$ \\
\hline Increased trust & $10.5 \%$ & Increased trust & $10.5 \%$ \\
\hline
\end{tabular}

\section{Consequence group: Product fidelity}

Product fidelity is a grouping of three consequences: learning about products, playing with products and having products visually presented. As a group, it was included in $39.5 \%$ of the ladders mentioned by consumers. Products that are displayed in virtual worlds can simulate more of a product's functions and provide a better view of its physical dimensions. Ultimately, product fidelity means consumers can get a better idea of what the product is actually like. This is related to the concept of virtual experience from Li et al. [8] who conclude that interacting with 3D models of products is closer to a "direct" experience with a product. Consequently, interacting with 3D models helps the consumer learn about products more effectively compared to learning from text and 2D images [19].

Consumer5: You would be able to see the scale of things, if [the dimensions] were accurate. I could even imagine trying a bed out in [...] my house to see it looks good next to all of my other things. 


\section{Consequence group: Interact with real people}

Virtual worlds are persistent real-time communication platforms. These attributes allow for real-time interactions with other people. Being able to interact with others is mentioned in $14.0 \%$ of the ladders. Interactions can be as simple as text chats with sales support personnel, friends or other consumers. However, interactions can also be more advanced; such as witnessing 'live' musical performances.

Interviewer: Is this different from how [musicians] promote themselves on a website?

Consumer28: YES (sic) because they can stream in and perform live

Interviewer: So is there something about a 'live' performance that makes it different?

Consumer28: It's an immersive experience that really feels like an intimate performance. Music is always best live when the musician can relate to the audience. Just like in [real life] the performer can connect with the audience.

\section{Consequence group: Increased trust}

Increased trust is about gaining confidence to make a purchase decision or gaining confidence to deal with a business. Consumers mention increased trust in $10.5 \%$ of the ladders. Trust is mentioned in relation to certain features of virtual worlds. For example, trust was mentioned alongside interacting with real people and interacting with high-fidelity products. It is also contingent on the type of products or services being bought.

Consumer6: I trust in many [businesses]. [...] For example I know you can pay for English class in [Second Life]. I think I could trust [them].

\section{Values}

Values relate to psychological needs and motivations. In Table 4, we summarise most frequently mentioned values by consumers.

Table 4. Summary of frequently mentioned values

\begin{tabular}{llll}
\hline Value Code & $\begin{array}{l}\text { Code } \\
\text { frequency }\end{array}$ & Value Group & Grouped frequency \\
\hline More knowledge & $22.8 \%$ & Knowledge & $36.0 \%$ \\
Informed decisions & $13.2 \%$ & Enjoyment & $23.7 \%$ \\
\hline Enjoyment & $23.7 \%$ & & \\
\hline
\end{tabular}

\section{Value group: Knowledge}

Knowledge implies the need to know more about products or the need to make informed decisions about buying products. It is the value in $36.0 \%$ of the ladders. Gaining knowledge is important because consumers ultimately have to make a purchase 
decision. Understandably, consumers want to gather as much information as they can about products (or the business) so that they make the right decision.

Consumer19: Maybe you don't know how it looks like; you could get an idea here [in Second Life].

Consumer21: You don't want to spend money on things you will never use or looks bad.

\section{Value group: Enjoyment}

Enjoyment relates to having a fun and stress-free experience. Many consumers think that shopping in virtual worlds can be more enjoyable than shopping on websites: $23.7 \%$ of the ladders have enjoyment as their value.

Consumer9: You can go anywhere [in Second Life] at the click of a button. Shop anywhere all round the world, buy ANYTHING :D (sic). No limits.

Interviewer: And you enjoy this?

Consumer9: yup

Interviewer: What makes being able to [go] anywhere enjoyable?

Consumer9: It's free, fast, can go with anyone

Interviewer: Do you get the same feeling when you browse websites?

Consumer9: ummm naah (sic). That gets boring lol

Interviewer: Why is going from website to website boring, but going from shop to shop in [Second Life] fun?

Consumer9: Because you can walk around here, be with others, try things on, meet others.

\subsection{Relationship between Attributes, Consequences and Values}

Figure 1 shows the hierarchal value map based on our analysis (please see section 5.2). The thickness of the lines between codes in the map indicates a higher link frequency between the codes. Functional consequences noted in the map relate to observable outcomes, whereas psycho-social consequences relate to personal outcomes (such as a change in emotion or thought).

From the map, we can derive the reasons why and when consumers may choose virtual worlds over websites. We call these reasons "motivational patterns", a term from Gengler et al. [20]. To derive motivational patterns, we start with the values at the top of the map and then follow the links downwards.

- Motivational pattern 1 is about enjoying the experience. This comes often from discovering new products and interacting with people. The $3 \mathrm{D}$ multiuser environment facilitates discovering new products and interacting with people.

- Motivational pattern 2 is about acquiring information about products. Consumers gather information about products by interacting with 3D simulations of products in virtual stores. Consumers also learn by interacting with store attendants in $3 \mathrm{D}$ spaces. 


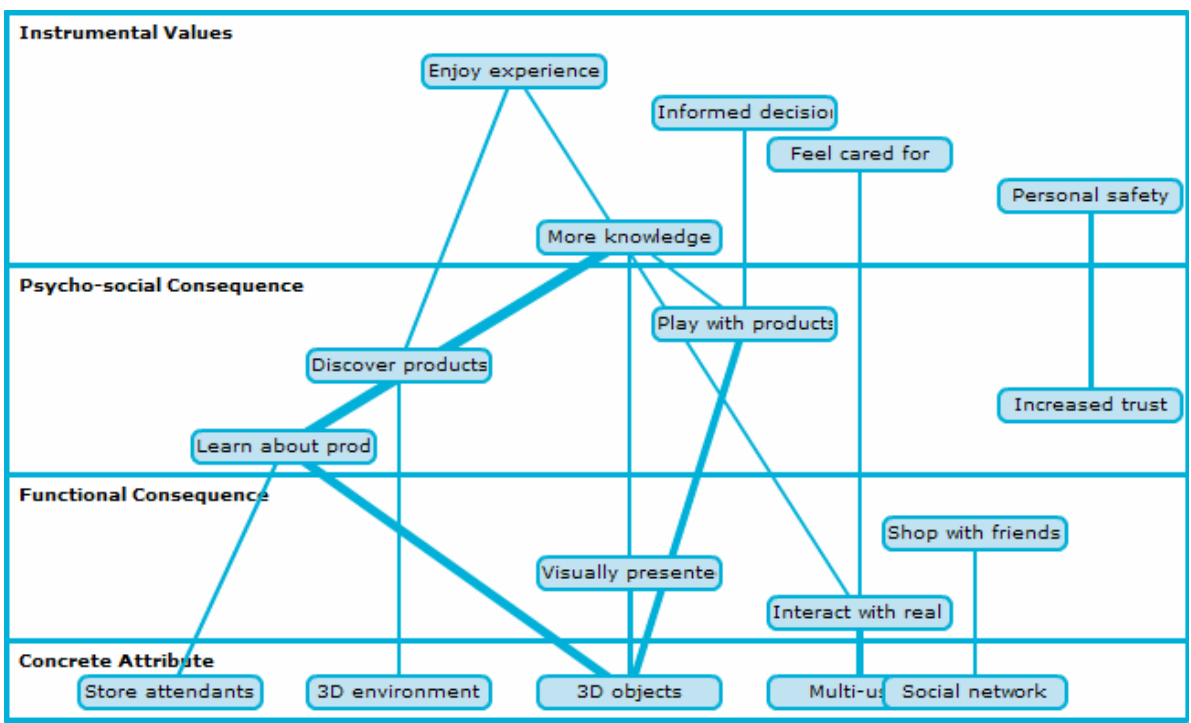

Fig. 1. Hierarchical value map with cut-off level at 4

- Motivational pattern 3 is about making informed decisions. This is possible because consumers can interact with virtual simulations of products, which are rendered and displayed in a 3D environment.

- Motivational pattern 4 is about feeling cared for. Consumers feel cared for because they are interacting with real people, which is possible because a virtual world is a multi-user environment.

- Motivational pattern 5 is about personal safety. Personal safety refers to concerns about privacy: for example, protecting personal information and banking details. Personal safety and privacy are related to trust. Consumers perceive interactions in virtual worlds to be more trustworthy because the interactions are interpersonal and because there are ways to verify a business's real world identity from websites or their stores.

These motivational patterns provide an understanding of how virtual worlds can enhance the e-commerce experience from the consumer's perspective. In the next subsection, we discuss affordances and answer the original research question.

\subsection{Which Affordances of Virtual Worlds Can Enhance Consumers' E-commerce Experiences?}

The research question for this study was, "which affordances of virtual worlds can enhance consumers' e-commerce experiences?" We answer this question by returning to the hierarchical value map (Figure 1, section 6.2). To identify the affordances, we start with the attributes from the map and then follow the links from the attributes upwards. Thus, the affordances that can enhance consumers' experiences are: 
- Affordance 1: Multi-user environments to allow shopping with others

- Affordance 2:3D environments to allow products to be easily discovered

- Affordance 3: Store attendants and 3D objects to support product learning

- Affordance 4: 3D objects to support more interactivity with products

- Affordance 5: Social networks to increase consumer's trust

We discuss implications of these affordances and consumers' perceptions of the affordances in the next section.

\section{Implications for Theory}

\subsection{Technology Acceptance}

Understanding consumers' perceptions of virtual world affordances can help predict why virtual worlds may be adopted by consumers for the e-commerce service encounter. Two dimensions of perception that are highly correlated with technology acceptance are perceived usefulness and perceived ease-of-use [21]. Usefulness refers to how proficiently a user will be able to complete a task with a technology. Ease-of-use refers to how easily a user can learn and utilise a technology. Both dimensions will be discussed in relation to virtual world affordances.

This study suggests that virtual worlds are perceived to be useful when the task is to learn about products. Virtual worlds are also perceived to be useful for interacting with other people. Therefore, consumers are likely to use virtual worlds for ecommerce when they want to learn about products or interact with others in a more effective and efficient manner.

This study indirectly addresses the dimension of perceived ease-of-use. Perceived ease-of-use is alluded to by our findings on enjoyment. Enjoyment, more commonly conceptualised as satisfaction, is related to usability. In turn, usability is related to ease-of-use [22]. Consumers may choose to use virtual worlds for e-commerce when they want to enjoy the e-commerce experience. To what extent the hedonic aspect (enjoyment) and utilitarian aspects (efficiency and effectiveness) overlap is uncertain. However, our study suggests that consumers perceive virtual worlds have the ability to offer both enjoyment and utility.

Four other dimensions of consumer's perceptions also emerged from our study. The dimensions are: compatibility, perceived service quality, perceived trust and information richness. These dimensions are also part of a website technology acceptance model by Chen and Tan [23].

Compatibility refers to the overlap between the consumers' personal beliefs and what they believe the technology represents. In other words, it relates to prejudices consumers' hold for or against a technology. The concept of compatibility originates from Rogers' theory on diffusion of innovations [24]. Bessiere et al. [25] describes an example of how compatibility can influence virtual world acceptance. They found users in their study associated virtual worlds "primarily with socialising and playing, rather than working". The belief that virtual worlds offer a playful rather than a serious environment was an adoption barrier. Similarly, consumers may have prejudices against adopting virtual worlds for e-commerce as they may think that virtual worlds are not for making real world transactions. 
Service quality is another dimension of consumers' perception. Service quality refers to the expectations of consumers about the service they will receive from a business. One facet of service quality is empathy, which is defined as "caring, individualised attention" towards consumers [26]. Our study found that empathy could be an advantage of shopping in virtual worlds. Consumers in our study explained that virtual worlds allow them to interact synchronously with sales personnel; the sales personnel were then able to answer questions immediately and in a personalised manner. Therefore, the interactions in virtual worlds were perceived as involving more empathy.

Consumers in our study perceived trust as another advantage of virtual worlds. However, trust varies depending on the situation. Consumers were not trusting of virtual worlds when making a transaction, but they were trusting of virtual worlds for advice. Consumers trust advice in virtual worlds because it comes from real people with whom they feel were co-present. The realism of the shopping environment may also be a reason for consumer's increased trust [27].

Information richness is the last dimension we discuss. Information richness is defined as "quality of product information and the extent of product comparison" [23]. Information richness enables the consumer to make an informed purchase decision. It relates to product learning, but also to the search, sense-making and decision-making process. Several consumers in our study discussed aspects relating to information richness. The 3D environment and 3D simulations help increase information richness. The interactions with other consumers and sales personnel also help consumers gather more information while in virtual worlds. Therefore, in terms of technology acceptance, information richness is another explanation why consumers' may choose virtual worlds for e-commerce.

\subsection{Multi-channel Consumption and the Service Encounter}

In the previous sub-section, we discussed some opportunities and barriers for adoption of virtual worlds for e-commerce. In this sub-section, we start with the assumption that virtual worlds are already a viable option for e-commerce. Another question then arises: when will consumers choose to use virtual worlds instead of other service channels?

Consumers have many options of channels during a service encounter, such as websites, high street, telephone, and so on. Virtual worlds are not likely to replace any of the existing service channels; more likely, virtual worlds will become another option to complement the existing channels. Research on multi-channel consumption behaviour suggests perceived risk, need for interpersonal contact, convenience, and price differential are factors that determine which channel consumers will choose for the service encounter [28]. Furthermore, research suggests consumer's choice of channel is context-specific and idiosyncratic [13]. Our study identifies some contexts where virtual worlds can enhance the service encounter, such as when consumers need to talk to sales personnel, have the desire to browse or when they would like to interact with 3D simulations of products.

Different service channels have different affordances. Our study contributes towards identifying the affordances of virtual worlds that make virtual worlds a unique service channel. Understanding the key affordances of virtual worlds can help designers make decisions on how to best utilise virtual worlds during a service encounter. 
For example, the consumer may want to learn about a product without leaving their home, but is disappointed with the images or product descriptions on websites. The consumer could instead enter a virtual world to interact with 3D simulations and discuss the product with sales personnel, or ask family and friends to accompany them to 3D stores to help in the decision-making process. Then, the consumer could return to the website to complete the purchase transactions because they may perceive the website is trustworthy and the payment will be handled securely.

\section{Practical Implications for E-commerce on Websites}

In some cases, it may not be practical to have the service encounter entirely in a virtual world. In these cases, affordances can be abstracted and incorporated into the design of e-commerce websites. In this section, we discuss five key affordances of virtual worlds for e-commerce that can be incorporated into websites. The five affordances we discuss are: facilitating co-presence, greater support for product discovery, virtual experience, playful experience with products, and building trust through interpersonal interactions. These affordances are related to the affordances mentioned in section 6.3 .

\section{Allowing the feeling of co-presence}

Websites should build features to support co-presence [29]. For example, co-presence can be supported through a chat feature embedded into websites. Shopping on websites would then become a collaborative activity, allowing consumers to shop 'together'. There is an inherent trade-off in privacy and anonymity with this affordance. However, in some situations, consumers may desire it. Based on our study, this affordance is related to the personal desire to enjoy the experience.

\section{Greater product discovery and browsing opportunities}

Websites should build features for product discovery through browsing. Browsing is a different kind of information-seeking behaviour from searching [30]. With browsing, the consumer does not necessarily know what they are looking for. Many e-commerce websites are designed for efficient search, but not for efficient browsing. Our study suggests that consumers appreciate the ability to browse as well during e-commerce. 3D environments, which have rich visuals, can facilitate browsing. On websites, rich visuals can be combined with intelligent recommender systems to provide consumers opportunities to browse products online.

\section{Having virtual experiences with products}

Websites should include features to provide an increased interactive experience with products to reproduce the virtual experiences that consumers have from using virtual worlds. Virtual experiences results from interacting with 3D rendered products that are "moveable, rotatable, zoomable, customizable, and animated" [19]. Another advantage of incorporating virtual experiences is that consumers feel more engaged 
when they learn with $3 \mathrm{D}$ objects compared to learning about products through text and $2 \mathrm{D}$ images [8].

\section{Having playful experiences with products}

Websites should build features to allow consumers to play with products. This is closely related to the affordance of having virtual experiences. However, playful experiences result in more than just learning about a product. Playful experiences result in engagement and enjoyment as well. The key feature related to playfulness is flexibility to manipulate virtual products in different contexts. For example, consumers discussed mixing and matching clothing items or rearranging different furniture pieces in a room. To support play and playfulness, websites should consider increasing their product selection (variety), adding elements onto their website that are modifiable and adding elements that do not directly serve utilitarian purposes [31].

\section{Building trust through social networks and interpersonal interaction}

Websites should support some form of social networking to allow consumers to connect and communicate with each other. This affordance is perceived to enhance trust. Trust, in this case, might come from having social capital. This is sometimes called "social trust" and it is correlated with a higher probability that consumers will make purchase transactions [32]. Large online retailers (e.g. amazon.com and ebay.com) have incorporated this feature with success by allowing customers to review products on their websites.

\section{Limitations and Directions for Further Study}

This study provides an empirically-grounded understanding of virtual world affordances for e-commerce. However, as with any empirical research, validity and generalisability should be considered in relation to how the data was collected and sampled. The participant sample for our study was experienced users of virtual worlds. Therefore, we presume the participants already enjoy using virtual worlds. They may also be more trusting of interactions in virtual worlds because of their familiarity with places, people and the interface in virtual worlds. Participants who are inexperienced with virtual worlds may have different perceptions compared to the participants in our study. Further studies with participants who are inexperienced with virtual worlds could provide more perspectives to complement the findings of this study.

Another point worth considering is that the experiences of our participants were based on their consumption of virtual items. Although the consumption processes may be similar for real and virtual items, there is still uncertainty about how much can be generalised about the use of the virtual world affordances for purchase of real world items. Further studies may want to look at consumption tasks in virtual worlds involving real items. However, this latter option is difficult given the scarcity of real world e-commerce in virtual worlds. Another option would be to perform laboratory studies where the consumption tasks and the choice of products can be controlled.

The communication mode used to collect data may be another limitation on the data. Using private text messages could influence the type and range of responses 
elicited during the laddering interviews. Other methods of collecting qualitative data, such as face-to-face interviews or online voice interviews, may provide a different range of responses. For example, if interviewed face-to-face, participants may be more aware of the benefits of interpersonal contact.

Finally, consumers' perceptions were based on interactions in Second Life. Second Life is one amongst many virtual worlds. The service encounter in Second Life is likely to be different from the service encounters in other virtual worlds because there would be differences between storefronts, personnel and interface designs. One solution would be to replicate the study using other virtual worlds, even with those that are not designed specifically for e-commerce, such as World of Warcraft [33].

\section{Conclusion}

This study explored the potential for utilising virtual worlds as an e-commerce service channel. The study shows that consumers' perceive virtual worlds to retain the convenience of an online service channel, but have additional affordances normally associated with offline service channels. These additional affordances are co-presence, product discovery, virtual experience with products, greater freedom to interact with products, and sociability. By identifying these affordances, and identifying consumers perceptions related to them, we have provided some direction for future research. We also provided priorities for interaction design of business-to-consumer e-commerce on websites and in virtual worlds.

\section{References}

1. Rymaszewski, M., Au, W.J., Ondrejka, C., Platel, R., Gorden, S.V., Cezanne, J., et al.: Second Life: The Official Guide, 2nd edn., pp. 360-362. Wiley Publishing, Indiana (2008)

2. Goel, L., Prokopec, S.: If You Build it Will They Come? An Empirical Investigation of Consumer Perceptions and Strategy in Virtual Worlds. Electron. Commer. Res. 9, 115-134 (2009)

3. Park, S.R., Nah, F.F., Dewester, D., Eschenbrenner, B.: Virtual World Affordances: Enhancing Brand Value By Virtual World Affordances: Enhancing Brand Value. Journal of Virtual Worlds Research 1(2), 1-18 (2008)

4. Barnes, S., Mattsson, J.: Brand Value in Virtual Worlds: An Axiological Approach. Journal of Electronic Commerce Research 9(3), 195-206 (2008)

5. Cagnina, M., Poian, M.: Beyond E-Business Models: The Road to Virtual Worlds. Electron. Commerce Res. 9(1), 49-75 (2009)

6. Norman, D.A.: Affordance, Conventions, and Design. Interactions, 38-42 (May/June 1999)

7. Bakshy, E., Simmons, M.P., Huffaker, D.A., Teng, C.Y., Adamic, L.A.: The Social Dynamics of Economic Activity in a Virtual World. In: Fourth International AAAI Conference on Weblogs and Social Media (2010)

8. Li, H., Daugherty, T., Biocca, F.: Characteristics of Virtual Experience in Electronic Commerce: A Protocol Analysis. J. Interact. Market. 15(3), 13-30 (2001)

9. Kozinets, R.V.: E-Tribalised marketing?: The Strategic Implications of Virtual Communities of Consumption. Eur. Manag. J. 17(3), 252-264 (1999) 
10. Wansink, B.: Using Laddering to Understand and Leverage a Brand's Equity. Qual. Market. Res. Int. J. 6(2), 111-118 (2003)

11. Veludo-De-Oliveira, T.M., Ikeda, A.A.: Discussing Laddering Application by the MeansEnd Chain Theory. The Qualitative Report 11(4), 626-642 (2006)

12. Bitner, M.J., Booms, B.H., Tetreault, M.S.: The Service Encounter: Diagnosing Favorable and Unfavorable Incidents. J. Market. 54(1), 71-84 (1990)

13. Dijk, G.V., Minocha, S., Laing, A.: Consumers, Channels and Communication: Online and Online Communication in Service Consumption. Interact. Comput. 19, 7-19 (2007)

14. Hemp, P.: Are You Ready for E-tailing 2.0? Harvard Business Review, 28 (June 2006)

15. Davis, F.D.: Perceived Usefulness, Perceived Ease of Use, and User Acceptance of Information Technology. MIS Quarterly 13(3), 391 (1989)

16. Second Life Community Standards

(2011), http://secondlife.com/corporate/cs.php

17. Reynolds, T.J., Gutman, J.: Laddering Theory, Method, Analysis, and Interpretation. J. Advert. Res. 28(1), 11-32 (1988)

18. Abeele, V., Zaman, B.: Laddering the User Experience, http://ladderux.org/papers/Laddering_the_User_Experience.pdf

19. Zhenhui, J., Benbasat, I.: Virtual Product Experience: Effects of Visual and Functional Control of Products on Perceived Diagnosticity and Flow in Electronic Shopping. J. Manag. Inform. Syst. 21(3), 111-147 (2004)

20. Gengler, C., Mulvey, M., Oglethorpe, J.: A Means-End Analysis of Mothers' Infant Feeding Choices. J. Publ. Pol. 18(2), 172-188 (1999)

21. Legris, P., Ingham, J., Collerette, P.: Why Do People Use Information Technology? A Critical Review of the Technology Acceptance Model. Inform. Manag. 40(3), 191-204 (2003)

22. Lederer, A.L., Maupin, D.J., Sena, M.P., Zhuang, Y.: The Technology Acceptance Model and the World Wide Web. Decis. Support Syst. 29(3), 269-282 (2000)

23. Chen, L.D., Tan, J.: Technology Adaptation in E-commerce: Key Determinants of Virtual Store Acceptance. Eur. Manag. J. 22(1), 74-86 (2004)

24. Rogers, E.M.: Diffusion of Innovations, 5th edn. The Free Press, New York (2003)

25. Bessiere, K., Ellis, J.B., Kellogg, W.A.: Acquiring a Professional "Second Life:" Problems and Prospects for the Use of Virtual Worlds in Business. In: 27th International Conference on Human Factors in Computing Systems, pp. 2883-2898 (2009)

26. Buttle, F.: SERVQUAL: Review, Critique, Research Agenda. Eur. J. Market. 30(1), 8-32 (1996)

27. Nassiri, N.: Increasing Trust Through the Use of 3D E-commerce Environment. In: 23rd ACM Symposium on Applied Computing, pp. 1463-1466 (2008)

28. Black, N.J., Lockett, A., Ennew, C., Winklhofer, H., McKechnie, S.: Modelling Consumer Choice of Distribution Channels: An Illustration from Financial Services. Int. J. Bank Market. 20(4), 161-173 (2002)

29. Gerhard, M., Moore, D., Hobbs, D.: Embodiment and Copresence in Collaborative Interfaces. Int. J. Hum. Comput. Interact. 61, 453-480 (2004)

30. Toms, E.: Understanding and Facilitating the Browsing of Electronic Text. International Journal of Human-Computer Studies 52(3), 423-452 (2000)

31. Chung, J., Tan, F.B.: Antecedents of Perceived Playfulness: an Exploratory Study on User Acceptance of General Information-Searching Websites. Inform. Manag. 41, 869-881 (2004)

32. Mutz, D.C.: Social Trust and E-Commerce: Experimental Evidence for the Effects of Social Trust on Individuals' Economic Behavior. Publ. Opin. Q 69(3), 393-416 (2005)

33. Bainbridge, W.S.: The Scientific Research Potential of Virtual Worlds. Science 317 (2007) 